\title{
Effect of concomitant statins on rituximab efficacy in patients with rheumatoid arthritis
}

Patients with rheumatoid arthritis (RA) are at an increased risk for cardiovascular disease. In order to lower this risk, statins are used in clinical practice in addition to biologics. ${ }^{1}$ Rituximab, an anti-CD20 antibody approved for the treatment of RA, induces B-cell apoptosis by crosslinking and redistributing CD20 to cholesterol-rich lipid rafts. ${ }^{2}$ Statins have been shown in vitro to induce conformational changes on the CD20 epitope, potentially influencing the apoptotic effect of rituximab. ${ }^{3}$

There are conflicting reports about the effect of statins on the clinical efficacy of rituximab in RA. ${ }^{4-6}$ We investigated the impact of statin coadministration on rituximab efficacy in patients from a global clinical trial programme in RA.

This was a retrospective, pooled, observed case analysis from four placebo-controlled phase II/III randomised clinical trials (DANCER, REFLEX, SERENE and IMAGE) $)^{7-10}$ in patients with moderate-to-severe active RA. All patients received concomitant methotrexate $10-25 \mathrm{mg} /$ week at a stable dose and were permitted to receive stable background doses of oral corticosteroids (prednisolone $\leq 10 \mathrm{mg} /$ day or equivalent) and non-steroidal antiinflammatory drugs throughout. Efficacy responses (change in Disease Activity Score 28 using erythrocyte sedimentation rate (DAS28-ESR) from baseline, American College of Rheumatology $20 \%$ or $50 \%$ (ACR20/50) response) and and peripheral blood CD19+ B-cell counts at 24 weeks following one course of rituximab were compared between patients who received concomitant statins for $\geq 8$ weeks ('statins', STY) and those who received statins for $<8$ weeks or not at all ('no statins', STN). Differences in outcome measures between STN and STY groups were tested using either an analysis of covariance model for continuous 
Table 1 Baseline demographics and disease characteristics of rituximab-treated and placebo-treated patients with RA

\begin{tabular}{lllll}
\hline & $\begin{array}{l}\text { Rituximab } \\
\text { STY (N=104) }\end{array}$ & $\begin{array}{l}\text { Rituximab } \\
\text { STN (N=1356) }\end{array}$ & $\begin{array}{l}\text { Placebo } \\
\text { STY (N=57) }\end{array}$ & $\begin{array}{l}\text { Placebo } \\
\text { STN (N=721) }\end{array}$ \\
\hline Female, \% & 71.2 & 82.5 & 77.2 & 80.7 \\
Age, mean (SD), years & $59.3(8.9)$ & $49.8(12.8)$ & $60.7(8.3)$ & $50.0(12.4)$ \\
Duration of RA, mean (SD), years & $7.8(8.4)$ & $6.8(8.0)$ & $8.4(7.6)$ & $6.8(7.6)$ \\
No. of previous DMARDs (excluding MTX), mean (SD) & $2.2(2.4)$ & $1.8(2.0)$ & $2.3(2.3)$ & $1.8(2.0)$ \\
No. of previous biologics, mean (SD) & $0.7(1.0)$ & $0.4(0.8)$ & $0.7(1.0)$ & $0.5(0.9)$ \\
Use of concomitant oral steroids, \% & 48.1 & 53.2 & 49.1 & 56.2 \\
RF and/or anti-CCP antibody positive, \% & 81.8 & 88.7 & 80.7 & 90.1 \\
DAS28-ESR, mean (SD) & $6.8(1.0)$ & $6.8(1.0)$ & $6.2(1.5)$ & $6.3(1.4)$ \\
\hline
\end{tabular}

Anti-CCP, anti-cyclic citrullinated peptide; DAS28-ESR, Disease Activity Score 28 using erythrocyte sedimentation rate; MTX, methotrexate; RA, rheumatoid arthritis; RF, rheumatoid factor; STN, no statins; STY, statins.

variables or logistic regression for categorical variables, adjusted for potential confounders such as age, treatment group, sex, RA duration, rheumatoid factor (RF) status and baseline DAS28-ESR. An analysis evaluating placebo-adjusted means of the results was also performed.

During the 24-week placebo-controlled period, 104 (7.1\%) of the 1460 rituximab-treated and $57(7.3 \%)$ of the 778 placebotreated patients received concomitant statins. STY patients were 10 years older, were more frequently men, had longer RA disease duration, were less frequently RF or anti-cyclic citrullinated peptide (anti-CCP) antibody positive and received more prior therapies than STN patients (table 1). At week 24, rituximab- treated STN patients demonstrated a greater mean $( \pm S D)$ decrease from baseline in DAS28-ESR $(-2.37 \pm 1.51)$ than STY patients $(-2.10 \pm 1.46)$; this was consistent with values observed in the placebo-treated STY and STN groups (figure 1A). These differences between STY and STN groups were not statistically significant. In both treatment groups, fewer STY patients achieved ACR20/50 responses at week 24 than STN patients (figure 1B). Placebo-adjusted mean difference for change in DAS28-ESR from baseline ( -0.09 (95\% CI -0.65 to 0.47$)$, $\mathrm{p}=0.7640)$ and placebo-adjusted ORs for ACR20 $(1.094(95 \%$ CI 0.49 to 2.45$), \mathrm{p}=0.8266)$ and ACR50 (0.775 (95\% CI 0.30 to 2.00$), \mathrm{p}=0.5977)$ responses between statin groups confirmed
A

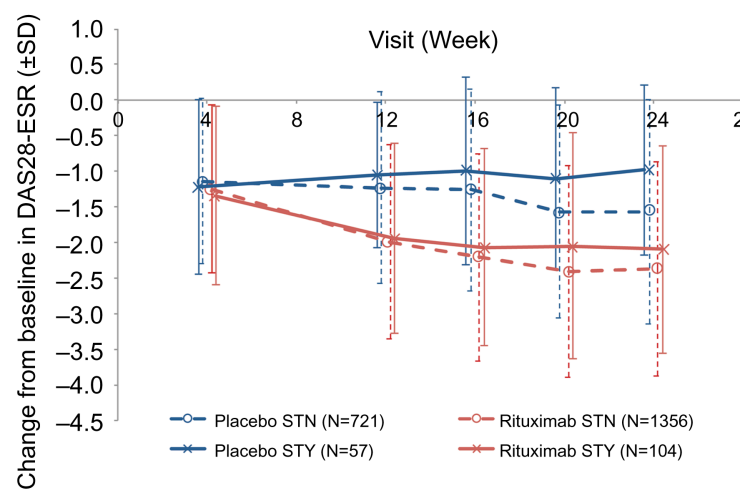

B

\begin{tabular}{|c|c|c|c|c|c|}
\hline ACR20 & $\begin{array}{l}\text { Placebo STN } \\
(n=721)\end{array}$ & $* \begin{array}{l}\text { Placebo STY } \\
(n=57)\end{array}$ & $\cdot \odot \begin{array}{l}\text { Rituximab STN } \\
(n=1356)\end{array}$ & $*$ & $\begin{array}{l}\text { Rituximab STY } \\
(n=104)\end{array}$ \\
\hline ACR50 & $\begin{array}{l}\text { Placebo STN } \\
(n=721)\end{array}$ & $* \begin{array}{l}\text { Placebo STY } \\
(n=57)\end{array}$ & $\begin{array}{l}\text { Q... Rituximab STN } \\
(n=1356)\end{array}$ & $*$ & $\begin{array}{l}\text { Rituximab STY } \\
(n=104)\end{array}$ \\
\hline
\end{tabular}
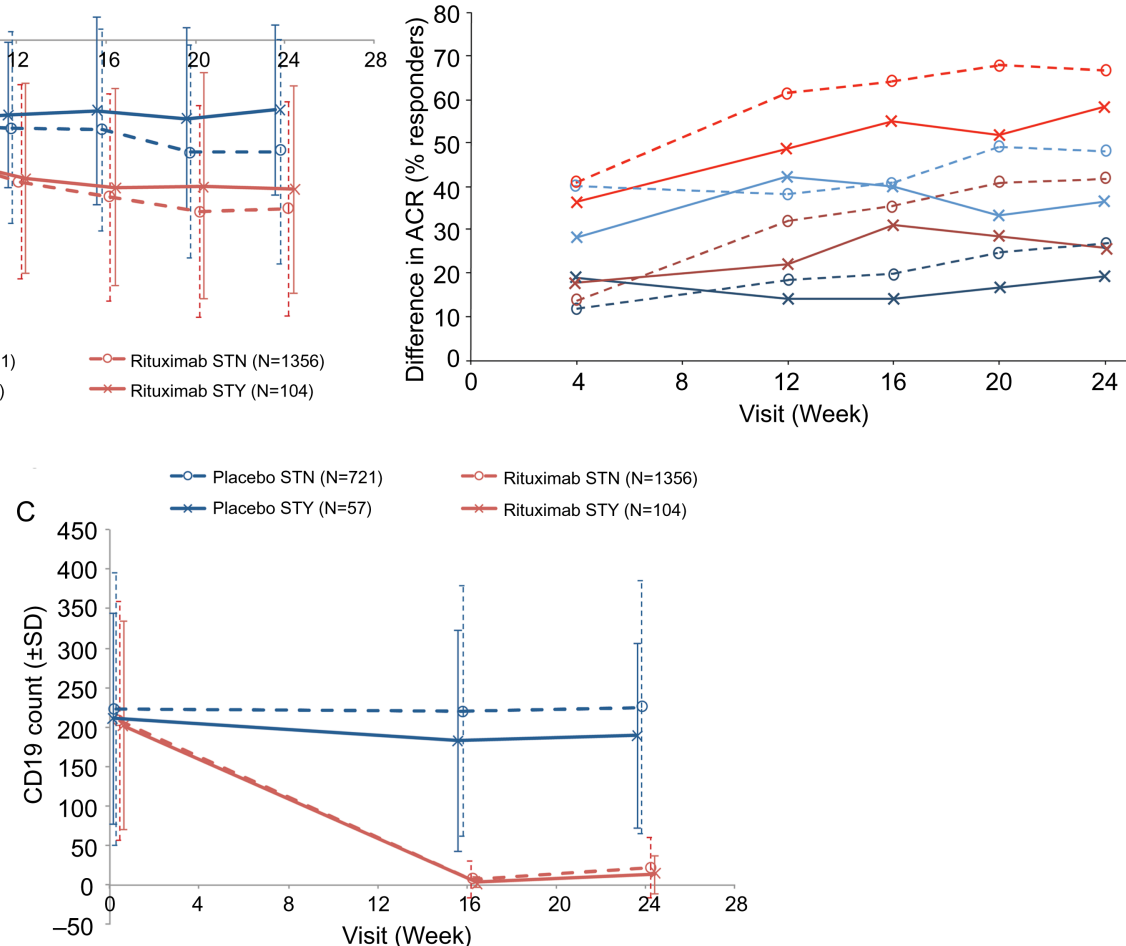

Figure 1 (A) Effect of concomitant statins on change from baseline in DAS28-ESR in rituximab-treated and placebo-treated patients with RA over a 24-week period; (B) Effect of concomitant statins on change from baseline in ACR20 and ACR50 response rates ${ }^{\mathrm{a}}$ in rituximab-treated and placebo-treated patients with RA over a 24-week period; (C) Effect of concomitant statins on change from baseline in peripheral blood CD19+ B-cell levels in rituximabtreated and placebo-treated patients with RA over a 24-week period. Observed data with no imputation made for missing data. Rituximab treatment group is pooled rituximab doses; data used are four pooled studies to week $24 .{ }^{a} A C R 20$ and ACR50 response rates calculated to original baseline. ACR20, American College of Rheumatology 20\% improvement criteria; ACR50, American College of Rheumatology 50\% improvement criteria; DAS28-ESR, Disease Activity Score 28 using erythrocyte sedimentation rate; PBO, placebo; RA, rheumatoid arthritis; RTX, rituximab; STN, no statins; STY, statins. 
there was insufficient evidence of a statin's effect on efficacy measures. CD19 counts were numerically, but not significantly, lower in STY patients than in STN patients at each visit (figure 1C).

Smaller reductions in DAS28-ESR and ACR20/50 responses were seen in the STY patients compared with the STN patients in both treatment groups that were not statistically significant. Placebo-adjusted tests showed that statin use did not significantly alter the treatment difference between rituximab and placebo. STY patients had longer disease duration and received more prior treatments, which may explain the lower ACR and DAS-28 responses in both the rituximab and the placebo groups. In contrast to previously published studies that reported on fewer than 30 patients, ${ }^{4-6}$ this is the first report from a large placebo-controlled dataset to assess the effect of statins on efficacy of rituximab. These findings suggest that concomitant use of statins did not significantly alter patient response to rituximab treatment over a 24-week placebo-controlled period.

\section{P B Lehane, ${ }^{1}$ S Lacey, ${ }^{1}$ E W Hessey, ${ }^{1}$ A Jahreis ${ }^{2}$}

${ }^{1}$ Roche Products Ltd, Welwyn Garden City, England, UK

${ }^{2}$ Genentech Inc, South San Francisco, California, USA

Correspondence to P B Lehane, Roche Products Ltd, Welwyn Garden City, England, UK; patricia.lehane@roche.com

Contributors All authors made substantial contributions to the conception of the work, the analysis and interpretation of the data, and drafting and revising the manuscript. All authors have approved of the version to be published and agree to be accountable for all aspects of the work in ensuring that questions related to the accuracy or integrity of any part of the work are appropriately investigated and resolved.

Funding This study was funded by F Hoffmann-La Roche Ltd and Genentech (A Member of the Roche Group). F Hoffmann-La Roche Ltd provided support for third-party writing assistance for this manuscript.

Competing interests PBL, SL and EWH are Roche employees; $\mathrm{AJ}$ is a Genentech employee.

Patient consent Obtained.

Ethics approval All participating sites received approval from their governing institutional review boards.

Provenance and peer review Not commissioned; externally peer reviewed.

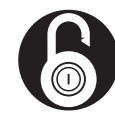

\section{OPEN ACCESS}

\section{REFERENCES}

1 De Vera MA, Choi H, Abrahamowicz M, et al. Impact of statin discontinuation on mortality in patients with rheumatoid arthritis: a population-based study. Arthritis Care Res (Hoboken) 2012;64:809-16.

2 Janas E, Priest R, Wilde JI, et al. Rituxan (anti-CD20 antibody) induced translocation of CD20 into lipid rafts is crucial for calcium influx and apoptosis. Clin Exp Immunol 2005:139:439-46.

3 Winiarska M, Bil J, Wilczek E, et al. Statins impair antitumor effects of rituximab by inducing conformational changes of CD20. PLoS Med 2008:5:e64.

4 Arts EE, Jansen TL, Den Broeder A, et al. Statins inhibit the antirheumatic effects of rituximab in rheumatoid arthritis: results from the Dutch Rheumatoid Arthritis Monitoring (DREAM) registry. Ann Rheum Dis 2011;70:877-8.

5 Das S, Fernandez Matilla M, Dass S, et al. Statins do not influence clinical response and $B$ cell depleation after rituximab treatment in rheumatoid arthritis. Ann Rheum Dis 2013;72:463-4.

6 Mazilu D, Gudu T, lonescu R, et al. Statins do not influence long-term rituximab clinical efficacy in rheumatoid arthritis patients. BioMed Res Int 2014;2014:689426.

7 Emery P, Fleischmann R, Filipowicz-Sosnowska A, et al. The efficacy and safety of rituximab in patients with active rheumatoid arthritis despite methotrexate treatment. Arthritis Rheum 2006:54:1390-400.

8 Cohen SB, Emery P, Greenwald MW, et al. Rituximab for rheumatoid arthritis refractory to anti-tumor necrosis factor therapy. Arthritis Rheum 2006;54:2793-806.

9 Emery P, Deodhar A, Rigby WF, et al. Efficacy and safety of different doses and retreatment of rituximab: a randomised, placebo-controlled trial in patients who are biological naive with active rheumatoid arthritis and an inadequate response to methotrexate (SERENE). Ann Rheum Dis 2010;69:1629-35.

10 Tak PP, Rigby WF, Rubbert-Roth A, et al. Inhibition of joint damage and improved clinical outcomes with rituximab plus methotrexate in early active rheumatoid arthritis: the IMAGE trial. Ann Rheum Dis. 2011;70:39-46.
Open Access This is an Open Access article distributed in accordance with the Creative Commons Attribution Non Commercial (CC BY-NC 3.0) license, which permits others to distribute, remix, adapt, build upon this work non-commercially, and license their derivative works on different terms, provided the original work is properly cited and the use is non-commercial. See: http://creativecommons.org/ licenses/by-nc/3.0/

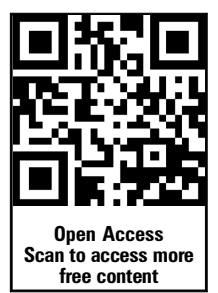

fro access more 